\title{
Climatic changes in the Urals over the past millennium - an analysis of geothermal and meteorological data
}

\author{
D. Yu. Demezhko ${ }^{1}$ and I. V. Golovanova ${ }^{2}$ \\ ${ }^{1}$ Institute of Geophysics UB RAS, Ekaterinburg, Russia \\ ${ }^{2}$ Institute of Geology, URS RAS, Ufa, Russia \\ Received: 21 December 2006 - Published in Clim. Past Discuss.: 10 January 2007 \\ Revised: 16 April 2007 - Accepted: 2 May 2007 - Published: 22 May 2007
}

\begin{abstract}
This investigation is based on a study of two paleoclimatic curves obtained in the Urals $\left(51-59^{\circ} \mathrm{N}, 58-61^{\circ} \mathrm{E}\right)$ : i) a ground surface temperature history (GSTH) reconstruction since 800 A.D. and ii) meteorological data for the last 170 years. Temperature anomalies measured in 49 boreholes were used for the GSTH reconstruction. It is shown that a traditional averaging of the histories leads to the lowest estimates of amplitude of past temperature fluctuations. The interval estimates method, accounting separately for the rock's thermal diffusivity variations and the influence of a number of non-climatic causes, was used to obtain the average GSTH.

Joint analysis of GSTH and meteorological data bring us to the following conclusions. First, ground surface temperatures in the Medieval maximum during 1100-1200 were $0.4 \mathrm{~K}$ higher than the 20th century mean temperature (19001960). The Little Ice Age cooling was culminated in 1720 when surface mean temperature was $1.6 \mathrm{~K}$ below the 20 th century mean temperature. Secondly, contemporary warming began approximately one century prior to the first instrumental measurements in the Urals. The rate of warming was $+0.25 \mathrm{~K} / 100$ years in the 18 th century, $+1.15 \mathrm{~K} / 100$ years in the 19 th and $+0.75 \mathrm{~K} / 100$ years in the first 80 years of the 20 th century. Finally, the mean rate of warming increased in the final decades of 20th century. An analysis of linear regression coefficients in running intervals of 21 and 31 years, shows that there were periods of warming with almost the same rates in the past, including the 19th century.
\end{abstract}

\section{Introduction}

One of the attribution approaches of recent climatic changes is based on studying instrumental climate records over periods of minimum anthropogenic impact and comparing them with modern climatic changes (Hansen and Lebedeff, 1987). However, the limited duration of meteorological records makes it impossible to assess normal climate characteristics and long-term variability (for several hundreds years). Temperature measurements in boreholes allow reconstruction of the ground surface temperature history (GSTH) over periods of several hundred to several thousand years. The purpose of our investigation is to reconstruct climatic history of the past 1000 years in the Middle and South Urals and to compare climate characteristics of the pre-industrial period (the 9th-19th centuries), when anthropogenic impacts were insignificant, with those of the second half or the last quarter of the 20th century.

\section{Geothermal data and reconstruction}

More than two hundred temperature logs in ore-prospecting boreholes of the Urals have been logged since the 1970s. From these, we have selected 49 borehole temperature logs in compliance with the following criteria: (a) depth of recording is not less than $700 \mathrm{~m}$; (b) no evidence of ground water flow; (c) no sharp contrasts of rock thermal properties; and (d) location within a region characterized by a single geological structure and common climatic history. Temperature logs included in the final sample were obtained from the boreholes drilled mainly on the eastern slope of the Middle and Southern Urals $\left(51-59^{\circ} \mathrm{N}, 58-61^{\circ} \mathrm{E}-\right.$ Fig. 1), where Paleozoic crystalline rocks crop out at the surface.

Correspondence to: D. Yu. Demezhko

(ddem54@inbox.ru)

Published by Copernicus Publications on behalf of the European Geosciences Union. 


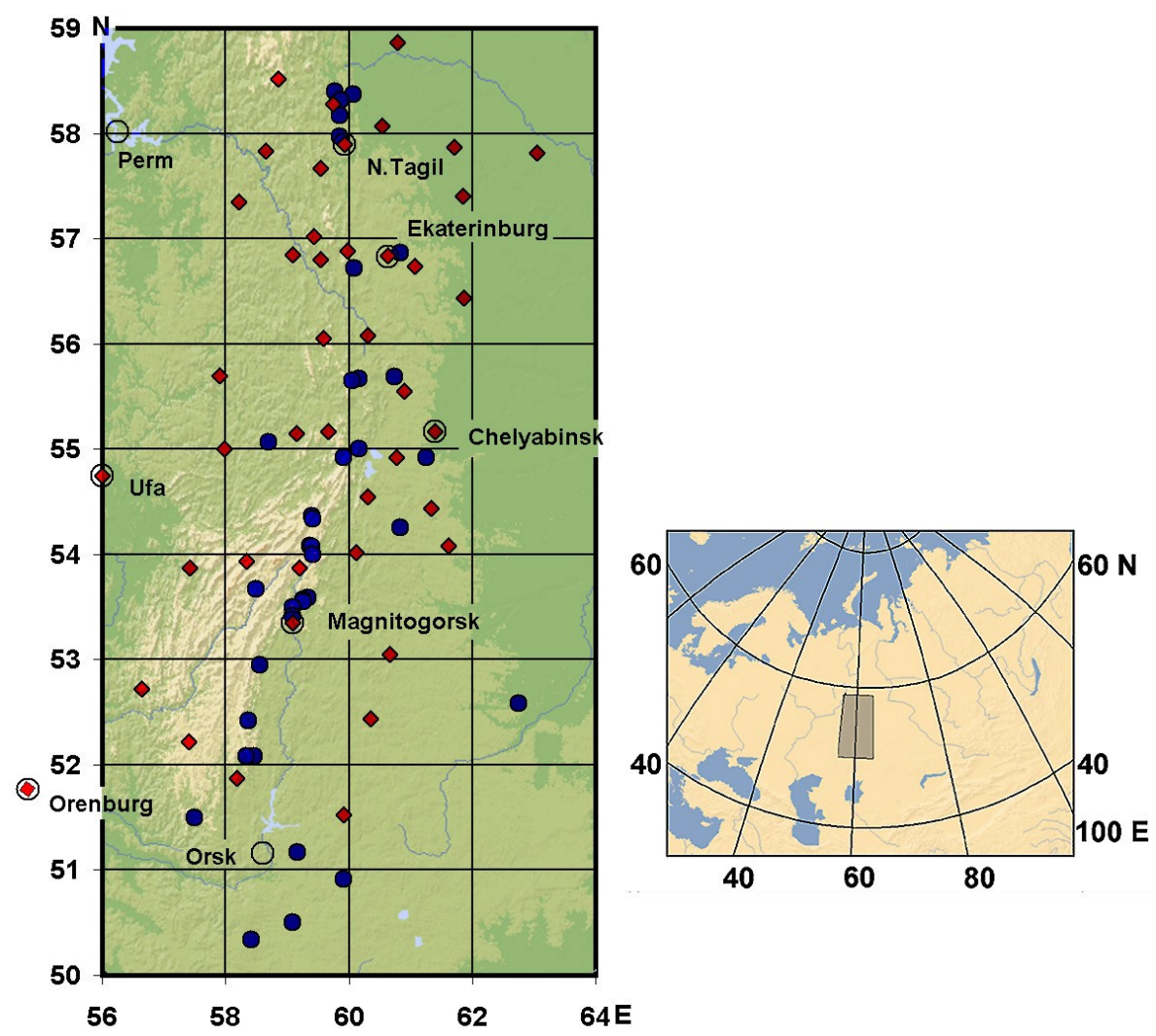

Fig. 1. Map of the studied region. Weather stations are shown as red rhombus, boreholes are shown as blue circles in the left panel. The right panel indicate the studied region position (grey trapezium) in Eurasia.

The left panel in Fig. 2 gives examples of borehole temperature logs included in the final sample. As the figure shows, the temperatures increase with depth almost linearly. Such temperature behaviour agrees with conductive heat transfer in thermally homogeneous media. Variations from the linear law are considered as temperature anomalies associated with climatically dependent variations of surface temperatures. A clearer understanding of the nature of these anomalies can be gained by reducing the measured borehole temperature logs (Fig. 2-right). The reducing procedure involves linear approximation of the lower section of a borehole temperature $\log$ (bearing interval) by the least-squares method, extrapolation of the linear trend to the earth surface, and computation of the difference between measured and extrapolated temperatures. To standardise the interpretation procedure we used an identical bearing interval of $720-900 \mathrm{~m}$ for all the borehole temperature logs.

A reconstruction of ground surface temperature histories (GSTH) for each borehole temperature log was obtained by solving the heat conduction boundary problem for thermally homogeneous media in relation to unknown parameters of the boundary condition at the surface. The algorithm of borehole temperature inversion, used in this study (Demezhko and Shchapov, 2001), allows reconstructions of GSTH as a step function with uneven time intervals: the duration of the intervals increase into the past. The pattern of reconstructed GSTHs looks much the same (Fig. 3): all reconstructions have temperature minima between 1600 and $1900 \mathrm{yrs}$ and temperature maxima between 800 and $1700 \mathrm{yrs}$. The maxima approximately correlate with the Medieval Warm Period (MWP), and the minima with the Little Ice Age (LIA). However, dates of the extremes vary. There are two principal causes for disagreement of the extremes: i) joint influence of a number of non-climatic causes (ground water flow, surface relief, changes in vegetation and snow cover); and ii) variations of mean rock thermal diffusivity from one borehole to another. The coefficient of thermal diffusivity $a$ dictates the rate of thermal wave propagation into rocks. In fact, the history argument is not time but the product of $a \times t$, where $t$ is the time interval between the climatic event and the date of thermal logging (years ago). A single value of the coefficient of thermal diffusivity is generally used in the palaeoclimatic analysis of several borehole temperature logs. In our case we took the mean for crystalline rocks of the Urals to be $a=10^{-6} \mathrm{~m}^{2} / \mathrm{s}$ (Demezhko, 2001; Golovanova, 2005). The actual variations of $a$ are equivalent to time-scale extension or reduction from the date of logging. Non-climatic causes reveal themselves as additional low-frequency noise. Hence 

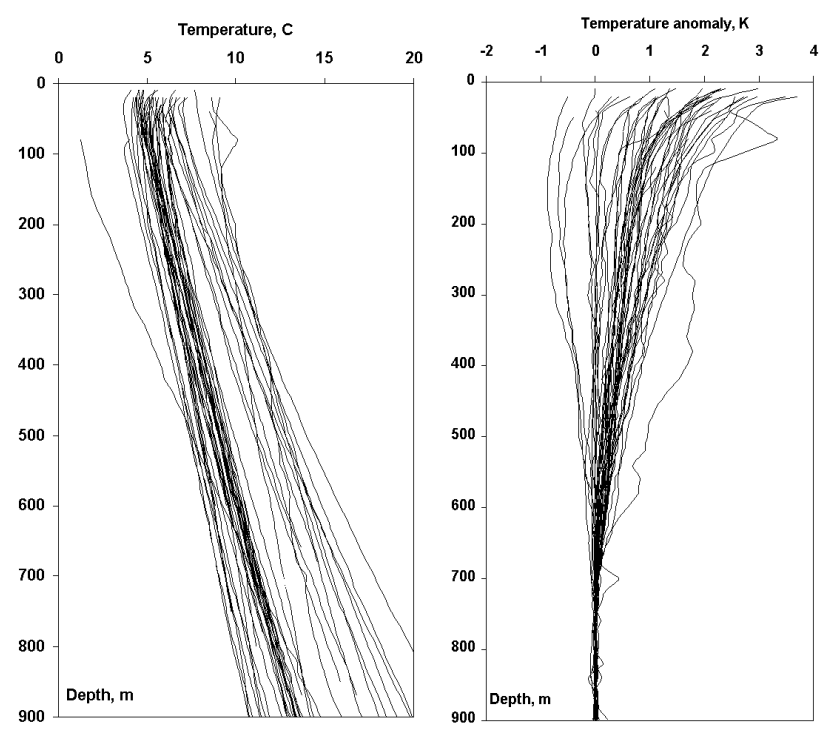

Fig. 2. Borehole temperature logs used in this study (left) and temperature anomalies calculated by reducing borehole temperature $\operatorname{logs}$ (right).

the reconstructed temperature history is the sum of the true history over the time scale (extended linearly in an arbitrary manner) and low-frequency noise.

To obtain the regional characteristic of GSTH we used the interval estimates method proposed by Demezhko et al. (2005), who showed that traditional averaging of individual GSTHs (minimum estimate) yield significantly underestimated amplitudes. Maximum estimates take into account the real position of minima and maxima identified as LIA and MWP on the time scale. Ignoring the presence of nonclimatic noise in the initial data makes the maximum estimate too high. The optimum estimate curve lies between minimum and maximum estimates and its position depends on the signal-to-noise ratio in the initial data. In our case the signal-to-noise ratio is equal to 1.25 and the optimal GSTH curve is close to the maximal estimate (Fig. 3).

Uncertainties in the averaged curve (minimum estimate) may be characterized by the standard error of the mean for any time cross-section, which is 7 times (root square of 49 number of reconstruction) less than the standard deviation of temperature. Vertical lines in Fig. 3 cover the interval "mean temperature \pm double standard error of mean", which approximately provide a $95 \%$ confidence limit. Although individual reconstructions differ substantially, the standard error of the mean does not exceed $0.12 \mathrm{~K}$. Differences between minimum and maximum estimates are larger $(0.5 \mathrm{~K}$ for LIA and 0.35 for MWP), and determine the main interval of uncertainty. The optimum curve presents the most probable history within the main interval of uncertainty.

The optimal GSTH has sufficiently higher amplitude of temperature variation than the same obtained earlier by the

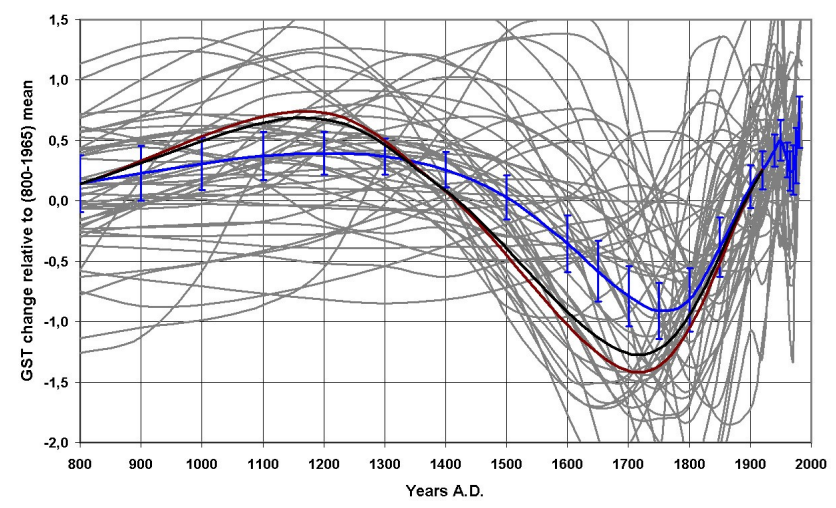

Fig. 3. Reconstructions of the GSTH. Pale curves denote individual reconstructions; blue -averaged history (minimum estimate; vertical lines denote \pm double standard error of mean: red - maximum estimate; black - optimum estimate.

partially overlapped sample of geothermal data (Pollack et al., 2003). For example, the temperature difference between 1720 and $1960 \mathrm{AD}$ in the Urals according to (Pollack et al., 2003 ) is about $0.7 \mathrm{~K}$ - two times less than the optimal estimate. There are a number of reasons for such disagreement: the mentioned paper used temperature profiles of less depth, the choice of reconstruction parameters, and the traditional averaging of individual GSTHs.

Under usual averaging of the GSTH curves applied by a number of researchers (Tyson et al., 1998; Pollack et al., 2003; Pollack and Smerdon, 2004) non-correlated noise is efficiently eliminated. In doing so the true amplitude is also reduced, i.e. the estimate of the mean temperature history is too low. In such cases an optimum procedure can be employed for deriving interval estimates of temperature amplitudes. Such estimates can be derived, provided that either non-climatic noise or variations in temperature diffusivity are taken into account separately.

\section{Meteorological data}

One of the basic characteristics representative of global climatic changes is surface-air temperature. Regular air temperature measurements have been taken in the Urals since the 19th century. Between 1930 and 1980 there were more than 150 weather stations in the Ural Region, but in the 1990s their number became considerably less. Our analysis involves data for 43 weather stations situated in the close vicinity of boreholes with geothermal information recorded (Fig. 1). All the records were taken from the Russian "Meteorological Bulletins". As compared with previous study of the Urals meteorological records (Štulc et al., 1997; Golovanova et al., 2001), this sample is spatially more compact and weather stations are located closer to the boreholes. 


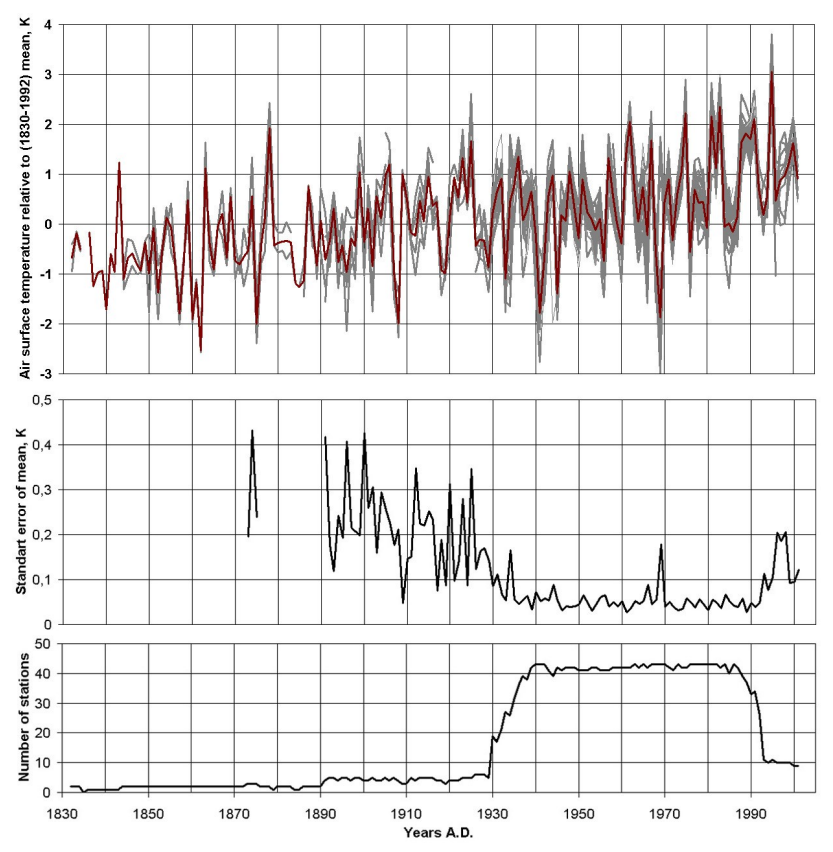

Fig. 4. Reduced air surface mean annual temperatures recorded in weather stations in the Middle and South Urals (pale curves in the upper panel). The averaged record is shown with a bold red line. The middle panel presenting standard error of mean, the bottom panel - the number of weather stations with the data on each time interval.

To evaluate regional variability of mean annual air temperatures we used the averaging procedure that takes into account the differences in the length of records and in the temperature constant - a latitudinal trend (Hansen and Lebedeff, 1987). Before averaging, each record was reduced by subtracting an individual value of temperature, the anomaly records were then averaged in the usual manner (Fig. 4). No homogeneity tests were performed. For the period 18901930 the standard error of the mean was about $0.2 \mathrm{~K}$, then it decreases to $0.05 \mathrm{~K}$ (1935-1990), and increases again in the last decade of the century. The total standard deviation of averaged mean annual air surface temperatures is about $1 \mathrm{~K}$. A synchronous pattern of the reduced records suggests that the eastern slope of the Middle and Southern Urals can be treated as a region of identical climatic history.

\section{Analysis of geothermal evidence and meteorological data}

Our comparative analysis is based upon two averaged datasets: surface air temperature over the past 170 years and the optimum estimation of ground surface temperature history over the past 1200 years obtained from geothermal evidence. The obtained GSTH reconstruction supports the idea that natural variability during the last millennium may be

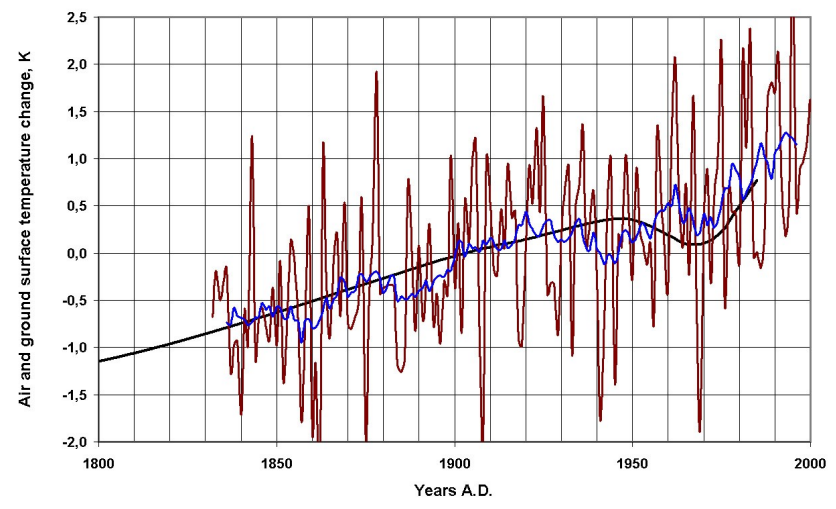

Fig. 5. Comparison of geothermal and meteorological data. Red curve - the reduced averaged record of air surface mean annual temperatures; blue curve - the same record smoothed out in the running 11-year interval; black curve - reconstructed ground surface temperatures (GSTH). The GSTH curve is slightly shifted along the temperature axis to enable an easier comparison.

larger than usually thought. This idea is also supported by a number of low-resolution proxies (including ice records, pollen and diatoms in lake sediments, foraminifers and stalagmites - see Moberg et al., 2005). According to pollen data the mean annual temperature in the MWP maximum (8801200 ) eastwards and westwards of the Urals was $0.7-0.2 \mathrm{~K}$ warmer than modern values (Klimenko, Klimanov, 2000). Reconstruction of upper treeline limit variations in the Polar Urals (Shiyatov, 2003) also shows that the upper timberline of larch in the 9-13 centuries was above its contemporary level, athough the treeline curve is shifted by $50-100$ years (to the recent times) relative to the geothermal one. We hypothesize that it is caused by a delayed response of forest's degradation/recovery to climate change.

The GSTH curve also may be directly compared with meteorological data (Fig. 5) during their period of overlap (1832-1985). The mean GSTH and air temperature rates of increase are approximately equal and come to 0.8 and $0.9 \mathrm{~K}$ per 100 years. A sharper temperature rise spanning the years 1970 to 1985 is also sufficiently reconstructed.

It should be noted that good agreement between ground and air surface temperatures (temperature trends) is not obligatory as a proof of reliable GSTH reconstructions. It is known that mean annual soil-air temperature difference in nothern regions is determined mainly by the insulation effect of snow cover (Beltrami and Marechal, 1991; Bartlet and Chapman, 1998; Demezhko, 2001; Smerdon et al., 2006). Mean annual ground surface temperature may change due to changing snow characteristics, even if air temperature is stable. Demezhko (2001) demonstrated the warming of ground temperatures due to snow in the Urals under conditions in which snow cover depth and annual amplitude of air temperature increased, while the mean annual air temperature decreased. During the last century, the mean annual 
precipitation slowly increased and the annual amplitude of air temperature decreased; the amount of snow in the Urals correlates with annual precipitation. Thus, the mean anuual soil-air temperature difference was relatively stable and the rate of GST increase was approximately equal to that of air temperature.

The shape of the optimum GSTH curve over the past 1200 years (Fig. 4) shows that surface temperatures in the MWP maximum (from 1100 to 1200 ) were $0.4 \mathrm{~K}$ warmer than the mean in the 20th century (from 1900 to 1960). LIA cooling events followed with a culmination in about 1720 when ground surface temperatures were $1.6 \mathrm{~K}$ colder than modern values. When analyzing the GSTH curve, one should bear in mind that geothermal information estimates temperatures averaged over increasingly longer periods back into the past. Any point on the GSTH curve ( $t$, yrs ago) represents a temperature averaged over the period $t \pm t / 3$ yrs ago (Demezhko, 2001). Thus, the actual trend of cooling might be more complicated and interrupted repeatedly with occasional warming events. Warming begun after the temperature minimum in 1720 was also irregular. Warming averaged $+0.25 \mathrm{~K} / 100 \mathrm{yrs}$ in the 18 th century, $+1.15 \mathrm{~K} / 100 \mathrm{yrs}$ in the 19 th century, and $+0.8 \mathrm{~K} / 100 \mathrm{yrs}$ in the first eighty-five years of the 20th century.

To estimate the average rates of air surface temperature changes over periods of different duration we applied the method of linear approximation. The average rate of air temperature changes during the period 1930 to 2001 is $+1.6 \mathrm{~K} / 100 \mathrm{yrs}$. Interestingly, the average rate calculated individually for weather stations near the larger cities (Nizhny Tagil, Ekaterinburg, Chelyabinsk, Ufa, Magnitogorsk, Orenburg) is essentially not different from that in the entire data sample. This suggests that urban heat islands, which certainly exist, are rather insignificant and do not affect air surface temperatures recorded at weather stations situated in the suburbs. One more interesting regional feature is revealed in the estimates of average rates in different latitudinal zones. From the south to the north the rates of warming decrease: $50-53^{\circ} \mathrm{N}-+2.1 \mathrm{~K} / 100 \mathrm{yrs}, 53-56^{\circ} \mathrm{N}-+1.6 \mathrm{~K} / 100 \mathrm{yrs}, 56-$ $59^{\circ} \mathrm{N}-+1.4 \mathrm{~K} / 100 \mathrm{yrs}$.

An idea of the temperature behaviour in time is given by the plots of slope coefficient of linear regression calculated in the running intervals of different length (Fig. 6). As the length grows, the amplitudes of the rates show a regular decrease. The sharpest warming took place during the 21-years periods $1963-1983$ (+6.1 K/100 yrs), 1860-1880 $(+5.7 \mathrm{~K} / 100 \mathrm{yrs})$ and the other six intervals when the rates of warming were somewhat slower. The most anomalous 31year periods fell on 1968-1998 (+4.5 K/100 yrs) and 19651995 (+4.5 K/100 yrs). In this case the difference from previous anomalies, with the rates of warming not more than $+2.6-+3.4 \mathrm{~K} / 100 \mathrm{yrs}$, seems to be wider. However, the confidence intervals calculated from the $t$-distribution (at $95 \%$ confidence), lies within $\pm 3 \mathrm{~K} / 100 \mathrm{yrs}$. This makes the difference of $1-1.5 \mathrm{~K} / 100 \mathrm{yrs}$ statistically insignificant.

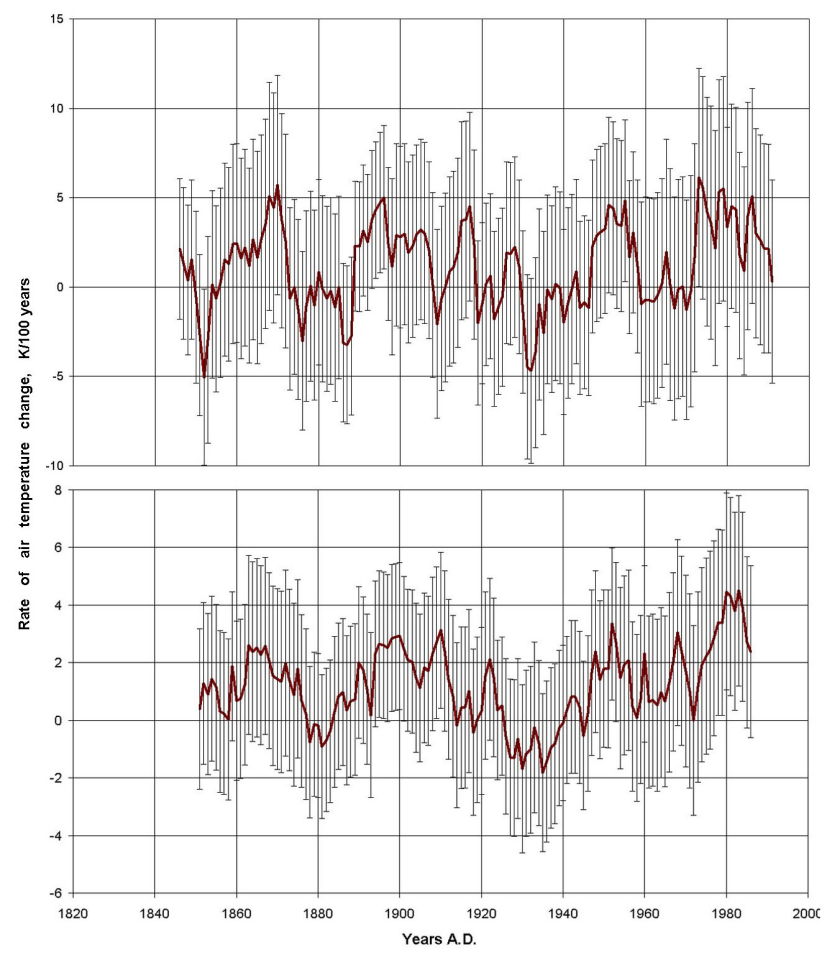

Fig. 6. Slope coefficients of linear regression (average rates of air surface temperature variations) calculated in 21-year (top panel) and 31-year (bottom panel) running intervals. Vertical lines show $95 \%$ confidence intervals.

\section{Conclusions}

1. Geothermal evidence (borehole temperature logs) recorded in the Urals and the developed procedure of their interpretation enable the surface temperature history over the last 1200 years to be reliably estimated. The obtained optimal GSTH estimate shows that natural variability during the last millennium may be larger than usually thought. According to this estimation, surface temperature in the Medieval Warm Period (MWP) spanning 1100 and $1200 \mathrm{AD}$ was $0.4 \mathrm{~K}$ warmer than the mean temperature of the 20th century (1900-1960) and surface temperature in the Little Ice Age in approximately $1720 \mathrm{AD}$ was $1.6 \mathrm{~K}$ cooler.

2. This study points out a good agreement between longterm variability of the ground surface temperature (reconstructed) and air surface temperature (measured) during their period of overlap (1832-1985). Both ground and air surface temperatures increased with mean rate $0.8-0.9 \mathrm{~K}$ per 100 years. Short-term variability of air surface temperature calculated in 21-year and 31-year running intervals reveals a slightly increased (but statistically insignificant) warming in the last decades of 20th century 
Acknowledgements. We are grateful to J. Smerdon for his constructive suggestions and improvements of the text, as well as to J. Majorowicz, R. Donner, and two anonymous reviewers for their critical comments. This work was supported by the Russian Foundation for Basic Research, project no 06-05-64084.

Edited by: J. Smerdon

\section{References}

Bartlett, M. G. and Chapman, D. S.: The timing, depth, and duration of snow events: implication for ground surface temperature histories recovered from boreholes, 1998 AGU Fall Meeteng abstracts, San Francisco, F842, 1998.

Beltrami, H. and Mareshal, J.-C.: Recent warming in eastern Canada inferred from geothermal measurements, Geophys. Res. Lett., 18, 4, 605-608, 1991.

Demezhko, D. Yu. and Shchapov, V. A.: 80,000 years ground surface temperature history inferred from the temperature-depth $\log$ measured in the superdeep hole SG-4 (the Urals, Russia), Global and Planetary Change, 29(1-2), 219-230, 2001.

Demezhko, D. Yu.: Geothermal method for palaeoclimate reconstructions (examples from the Urals, Russia), Ekaterinburg, UB RAS, 144 p., 2001 (in Russian).

Demezhko, D. Yu., Utkin, V. I., Shchapov, V. A., and Golovanova, I. V.: Variations in the Earth's Surface Temperature in the Urals during the Last Millennium Based on Borehole Temperature Data, Doklady Earth Sciences, 403, 5, 764-766, 2005.

Golovanova, I. V., Harris, R. N., Selezniova, G. V., and Štulc, P.: Evidence of climatic warming in the southern Urals region derived from borehole temperatures and meteorological data, Glob. Planet. Change, 29, 167-188, 2001.
Golovanova, I. V.: Thermal field of the South Urals, Moscow, Nauka, 189 pp, 2005 (in Russian).

Hansen, J. and Lebedeff, S.: Global trends of measured Air surface temperature, J. Geophys. Res., 92, 13 345-13 372, 1987.

Klimenko, V. V. and Klimanov, V. A.: Climate of the North Hemisphere in the Medieval Optimum, Doklady Akademii Nauk, 371, 4, 539-543, 2000 (in Russian).

Moberg, A., Sonechkin, D. M., Holmgren, K., Datsenko, N. M., and Karl'en, W.: Highly variable northern hemisphere temperatures reconstructed from low- and high resolution proxy data, Nature, 433, 613-617, 2005.

Pollack, H. N., Demezhko, D. Yu., Duchkov, A. D., Golovanova, I. V., Huang, S., Shchapov, V. A., and Smerdon, J. E.: Surface temperature trends in Russia over the past five centuries reconstructed from borehole temperatures, J. Geophys. Res., 108(A4), 2180, doi:10.1029/2002JB002154, 2003.

Pollack, H. N. and Smerdon, J. E.: Borehole climate reconstruction: Spatial structure and hemispheric averages, J. Geophys .Res., 109, D11106, doi:10.1029/2003JD004163, 2004.

Smerdon, J. E., Pollack, H. N., Cermak V., Enz, J. W., Kresl, M., Safanda, J., and Wehmiller J. F.: Daily, seasonal, and annual relationships between air and subsurface temperatures, J. Geophys. Res., 111, D07101, doi:10.1029/2004JD005578, 2006.

Štulc, P., Golovanova, I. V., and Selezniova, G. V.: Climate Change in the Urals, Russia, inferred from Borehole Temperature Data, Studia Geoph. et Geod., 41, 225-246, 1997.

Shiyatov, S. G.: Rates of changes in the upper treeline ecotone in the Polar Ural Mountains, Pages Newsletter, 11(1), 8-10, 2003.

Tyson, P. D., Mason, S. J., Jones, M. Q. W., and Cooper, G. R. J.: Global warming and geothermal profiles: The surface rocktemperature response in South Africa, Geophys. Res. Lett., 25, 14, 2711-2713, 1998. 